\title{
Estímulos geradores da raiva em estudantes com deficiência intelectual sob a perspectiva da Educação Emocional
}

\author{
Generating stimuli on intelectual disabled students under the perspective of \\ emotional education
}

Estímulos generadores de la rabia en estudiantes con deficiencia intelectual desde la perspectiva de la educación emocional

\author{
Taísa Caldas Dantas \\ Professora doutora na Universidade Federal da Paraíba, João Pessoa, Paraíba, Brasil. \\ taisa.cd@gmail.com \\ ORCID - https://orcid.org/0000-0002-3661-0025
}

Recebido em 21 maio 2019

Aprovado em 9 de setembro de 2020

Publicado em 9 de novembro de 2020

\section{RESUMO}

Este artigo tem como objetivo analisar os principais estímulos geradores da emoção da raiva em estudantes com deficiência intelectual a partir dos princípios da Educação Emocional. Diante de uma realidade de preconceito e exclusão vivenciada pelas pessoas com deficiência intelectual, o que afeta diretamente as suas emoções, a emoção da raiva é comumente vivenciada por esse grupo social, muitas vezes, de forma inconsciente e afetando diretamente seu bem-estar. Nesse contexto, a Educação Emocional surge como ferramenta pedagógica que deve ser incluída na escola, uma vez que oferece a possibilidade de 0 sujeito educar-se emocionalmente. $\mathrm{O}$ argumento central que norteia este estudo é que a emoção da raiva, quando vivenciada de maneira saudável através da Educação Emocional, pode contribuir para a superação de situações de vulnerabilidade que marcam a vida das pessoas com deficiência intelectual. Esta pesquisa adere à abordagem qualitativa e foi realizada por meio da observação direta e da entrevista semiestruturada, com 27 jovens com deficiência intelectual da Educação de Jovens e Adultos (EJA). As conclusões deste estudo apontam que o trabalho da emoção da raiva com estudantes com deficiência intelectual precisa ser melhor projetado e desenvolvido na escola, através da implantação de propostas na área da Educação Emocional, uma vez que este campo do conhecimento oportuniza ao sujeito um processo de autoconhecimento e regulação emocional que pode reconfigurar o conjunto de respostas agressivas e colaborar com o rompimento de situações de vulnerabilidade vivenciadas pelas pessoas com deficiência intelectual.

Palavras-chave: Educação emocional; raiva; deficiência intelectual.

\section{ABSTRACT}

This article aims to analyze the main stimuli that generate the emotion of anger in students with intellectual disabilities based on the principles of Emotional Education. Faced with a reality of prejudice and exclusion experienced by people with disabilities, which directly affects their emotions, the emotion of anger is commonly experienced by this social group, often unconsciously and directly affecting their well-being. In this 
context, Emotional Education emerges as a pedagogical tool that must be included in the school, since it offers the possibility for the subject to be emotionally educated. The central argument that guides this study is that the emotion of anger, when experienced in a healthy way through Emotional Education, can contribute to overcoming situations of vulnerability that mark the lives of people with disabilities. This research adheres to the qualitative approach and was carried out through direct observation and semi-structured interview, with 27 young people with intellectual disabilities from Youth and Adult Education (EJA). The conclusions of this study point out that the work of angry emotion with students with intellectual disabilities needs to be better designed and developed at school, through the implementation of proposals in the area of emotional education, since Emotional Education provides the subject with a process of self-knowledge and emotional regulation that can reconfigure the set of aggressive responses and help to break the vulnerability situations experienced by people with intellectual disabilities.

Keywords: Emotion education; rage; intellectual disability.

\section{RESUMEN}

Este artículo tiene como objetivo analizar los principales estímulos que generan la emoción de la ira en los estudiantes con discapacidad intelectual en base a los principios de la educación emocional. Frente a una realidad de prejuicio y exclusión experimentada por las personas con discapacidad, que afecta directamente sus emociones, la emoción de la ira es comúnmente experimentada por este grupo social, que a menudo inconsciente y directamente afecta su bienestar. En este contexto, la educación emocional surge como una herramienta pedagógica que debe incluirse en la escuela, ya que ofrece la posibilidad de que el sujeto sea educado emocionalmente. El argumento central que guía este estudio es que la emoción de la ira, cuando se experimenta de manera saludable a través de la Educación Emocional, puede contribuir a superar las situaciones de vulnerabilidad que marcan la vida de las personas con discapacidad. Esta investigación se adhiere al enfoque cualitativo y se llevó a cabo mediante observación directa y entrevista semiestructurada, con 27 jóvenes con discapacidad intelectual de la Educación de Jóvenes y Adultos (EJA). Las conclusiones de este estudio señalan que el trabajo de la emoción de enojo con estudiantes con discapacidad intelectual necesita ser mejor diseñado y desarrollado en la escuela, a través de la implementación de propuestas en el área de educación emocional, ya que la Educación Emocional proporciona al sujeto un proceso de autoconocimiento. y regulación emocional que puede reconfigurar el conjunto de respuestas agresivas y ayudar a romper las situaciones de vulnerabilidad que viven las personas con discapacidad intelectual.

Palabras clave: Educación emocional; rabia; deficiencia intelectual.

\section{Introdução}

Esta pesquisa faz parte de uma investigação maior realizada no âmbito do Núcleo de Educação Emocional de uma Universidade Federal Brasileira que tem como foco o estudo das emoções de estudantes com e sem deficiência da escola pública. Aqui, especificamente, o objetivo deste artigo é analisar os estímulos geradores da emoção da 
raiva em estudantes com deficiência intelectual a partir dos princípios da Educação Emocional.

O argumento central que norteia este estudo é que a emoção da raiva, quando vivenciada de maneira saudável através da Educação Emocional, pode contribuir para a superação de situações de vulnerabilidade que marcam a vida das pessoas com deficiência intelectual e, consequentemente, oportunizar a autonomia de indivíduos pertencentes a este grupo minoritário. Na mesma visão, Damasio (2017) e Possebon (2019) argumentam que o autoconhecimento proporcionado pela educação emocional é um processo libertador que pode quebrar cadeias na vida de um indivíduo e levá-lo a ser protagonista de sua história e emoções.

Atualmente, apesar das conquistas e mudanças de paradigmas referentes à concepção da deficiência, principalmente a partir da adoção do modelo social (ONU, 2006), os conceitos e as práticas relacionadas à sua caracterização continuam a ser influenciados por narrativas arcaicas, que, por muito tempo, classificaram a deficiência como uma patologia, ou como um castigo de forças maiores (GAUDENZI, ORTEGA, 2016). A partir desta realidade, visualiza-se um cenário de preconceitos, estereótipos e exclusão atribuídos socialmente às pessoas com deficiência.

No caso das pessoas com deficiência intelectual, foco deste estudo, a exclusão social é ainda mais agravada (MAZZOTA, 2005; MENDES, 2006), uma vez que a história ilumina que este grupo minoritário foi e continua a ser estigmatizado por possuírem mentes e corpos diferentes, corpos estes que são vistos sob a ótica biomédica como anormais (MELETTI e BUENO, 2011). Ademais, há inúmeras crenças infundadas no que tange ao seu desenvolvimento e à sua capacidade, perpetuam-se barreiras atitudinais que interferem na ascensão social deste grupo, bem como o afasta da participação nas esferas pública, política e nos espaços de saber-poder.

Neste estudo, as questões acerca da visibilidade das pessoas com deficiência intelectual emergem como uma possibilidade. A Educação Emocional, como ferramenta pedagógica libertadora descrita por Possebon e Possebon (2020), instrumentaliza o indivíduo para a busca do autoconhecimento a fim de promover a vivência consciente das emoções e torna-se, assim, um caminho para uma vida autônoma.

O peso de uma sociedade excludente pode repercutir significativamente na vivência saudável das emoções pelas pessoas com deficiência intelectual. Autores como Martins (2011); Mazzota (2005), Mendes (2006) e Rodrigues e Lima (2017) argumentam os 
http://dx.doi.org/10.5902/1984686X44426

malefícios históricos dessa exclusão para a construção de uma vida independente. De acordo com Bisquerra, Gonzaléz e Navarro (2015), a maioria dos problemas vivenciados pelos indivíduos têm sua origem no âmbito emocional, ou seja, quando a emocionalidade não está direcionada à uma experiência benéfica, a mente promove a perpetuação de situações desagradáveis ao sujeito. No mesmo sentido, Damásio (2013) compreende a emoção como um estado complexo de sentir, que resulta em mudanças físicas e psicológicas, influenciando o pensamento e o comportamento.

Nesse contexto, a Educação Emocional surge como um novo campo do saber, que oportuniza aos sujeitos a possibilidade de educar-se emocionalmente a partir da consciência das emoções. A Educação Emocional pode ser entendida como um processo educativo, contínuo e permanente, que pretende promover a dimensão emocional como complemento indispensável do desenvolvimento integral (BISQUERRA, 2014).

Para isso, o campo da Educação Emocional promove conhecimentos e habilidades acerca das emoções com o objetivo de capacitar o indivíduo para melhor responder aos desafios que surgem no dia a dia, visando aumentar o bem-estar pessoal e social (ARANDIGA e TORTOSA, 2013). No caso das pessoas com deficiência intelectual, as competências emocionais podem ser objetos de aprendizagem para que possam melhor responder às situações de preconceito e exclusão social que vivenciam.

As situações de discriminação são possíveis estímulos geradores de emoções experimentadas de maneira confusa e inconsciente, como, por exemplo, a emoção da raiva. A raiva pode ser caracterizada como uma resposta primária e imediata do organismo quando o indivíduo percebe-se impedido na realização de um objetivo ou na satisfação de uma necessidade (POSSEBON, 2017). Esta emoção prepara o corpo para o enfrentamento de situações consideradas ofensivas ou depreciativas (NAVAS; BOZAL, 2012) e é gerada quando a pessoa tem a sensação de ter sido prejudicada em algo (BISQUERRA, 2009). Nesse sentido, vale salientar que possíveis reações desproporcionais do organismo, advindas da falta de consciência sobre a emoção da raiva, podem ocasionar discussões, brigas corporais e também refletir na saúde do indivíduo.

Por outro lado, quando vivenciada de maneira saudável, a emoção da raiva pode ser vista como uma aliada na transposição de situações de vulnerabilidade frequentemente vivenciadas pelas pessoas com deficiência intelectual. De acordo com Casassus (2009), a competência emocional proporciona aos indivíduos a possibilidade de adquirir habilidades 
http://dx.doi.org/10.5902/1984686X44426

com relação às suas emoções e às dos outros, caracterizando-se por ser um processo de transformação e incorporação da consciência emocional.

Esse artigo adere à abordagem de pesquisa qualitativa, no qual serão investigados os estímulos que levam pessoas com deficiência intelectual a vivenciarem a emoção da raiva sob a ótica da Educação Emocional. A pesquisa será realizada através da observação direta e de um roteiro de entrevista semiestruturada, denominado "diário das emoções". O campo de pesquisa é uma Escola Estadual, pertencente a uma Fundação Paraibana, que atende pessoas com deficiências. Os sujeitos desta pesquisa são estudantes com deficiência intelectual da modalidade da Educação de Jovens e Adultos (EJA), inseridos em três turmas, totalizando 27 participantes.

A seguir, serão apresentados apontamentos teóricos sobre a emoção da raiva, depois o percurso metodológico adotado e, por fim, a análise de dados sobre os estímulos geradores da emoção da raiva entre jovens com deficiência intelectual.

\section{O universo das emoções e a raiva: apontamentos teóricos}

Antes de serem reconhecidas como fundamentais para o desenvolvimento do ser humano, as emoções foram, por muito tempo, renegadas e esquecidas. No chão das escolas, impera a hegemonia de um paradigma educacional que reprime a sensibilidade e a integralidade do ser, visando apenas os aspectos técnico-científicos, racionais e produtivos (BISQUERRA, 2009).

As discussões em torno da vivência das emoções são relativamente recentes. Nos últimos vinte anos, o estudo das emoções assumiu um papel fundamental em vários campos de conhecimento, inclusive no campo pedagógico. Os trabalhos nas neurociências, a partir da contribuição valiosa de Casassus (2009) e Antonio Damásio (2013), apontam que as emoções estão na base dos processos de decisão das ações humanas (GONSALVES e SOUZA, 2015).

Por outro lado, a vivência das emoções de forma inconsciente pode levar o indivíduo a experimentar situações corriqueiras de maneira desconfortável, prejudicando, consequentemente, o seu bem-estar físico e emocional (BISQUERRA, 2014). No que se refere às pessoas com deficiência intelectual, o cotidiano marcado pelo preconceito e pela exclusão passam a ser postos como aspectos decisivos para o desencadear das emoções, podendo acarretar experiências negativas quando estas não são trabalhadas internamente (DANTAS, 2018). 
A origem da palavra emoção está relacionada com um movimento interno gerado por um estímulo que afeta a nossa alma, trazendo consigo a ideia de movimento, distante de ser algo imutável ou estático (DAMÁSIO, 2013). De acordo com Possebon (2017, p. 18), define-se a emoção por "um conjunto complexo de interações subjetivas e objetivas que ocorrem mediante uma ativação, ou seja, mediante um acontecimento gerador". Sendo assim, é possível afirmar que a emoção é caracterizada como uma reação do organismo que o indivíduo expressa por meio de situações estimulantes.

As emoções primárias - alegria, tristeza, medo, raiva, nojo e surpresa - estão espalhadas por todo o globo e são pertencentes a todos, pois são emoções compreendidas como inatas e intrínsecas a todo ser humano. Como ratifica Martins (2004, p. 23), as "emoções são reações globais, inatas e passageiras que têm uma função específica na vida de cada ser", em que as respostas originadas por cada emoção detêm um papel particular diante de determinadas situações do cotidiano.

O papel das emoções na vida dos seres humanos é, portanto, central. Pode influenciar a personalidade, os comportamentos e repercutir positiva ou negativamente na saúde. As emoções, de acordo com Possebon (2017, p. 15):

Desempenham um papel central nas nossas vidas, especialmente por serem estruturantes no desenvolvimento de uma pessoa. Elas influenciam a personalidade, estão nos comportamentos, têm impactos na sua saúde. Além disso, as emoções estão na fonte da aquisição de competências fundamentais para lidar com exigências sociais.

Dentro do conjunto das emoções primárias, a emoção da raiva, foco deste estudo, é caracterizada por Possebon (2017, p.41) como "uma resposta primária e imediata do organismo quando se percebe impedido na consecução de um objetivo ou na satisfação de uma necessidade", o que traduz a possibilidade desta emoção oferecer uma relação de equilíbrio entre as funções biológicas do corpo e a necessidade que se tem em cumprir aquilo que the é desejado. Nas palavras de Casanova "et al" (2009, p. 9),

A raiva é uma emoção humana completamente normal, saudável, e uma determinada quantidade dela é necessária à nossa sobrevivência. [...] inspira os sentimentos e os comportamentos poderosos e agressivos, que permitem ao ser humano lutar e defender-se quando é atacado.

Corroborando com o autor, entende-se que a emoção da raiva é essencial para a sobrevivência e também caracteriza-se como uma necessidade natural do organismo, retirando, por consequência, o estigma socialmente estabelecido de que esta é uma emoção negativa, reconhecendo-a como fundamental para o desenrolar da vida. 
http://dx.doi.org/10.5902/1984686X44426

De acordo com Possebon (2017), a emoção da raiva sempre está presente em condutas agressivas, entretanto, se para uma conduta agressiva ser despertada é necessária a emoção da raiva, em contrapartida a raiva não leva, automaticamente, à agressão. Vale salientar que a raiva não é uma emoção manifestada exclusivamente por um determinado grupo social e também não pode ser atribuída como uma emoção específica a um determinado gênero, pois as condutas de maltrato atravessam indivíduos de diferentes nacionalidades, culturas, etnias, gêneros, faixas etárias, dentre outras especificações (MIRA e LOPEZ, 2012).

A raiva "pode ser causada por fatores internos e externos, e como outras emoções, ao sentirmos esta emoção, o batimento cardíaco e a pressão sanguínea aumentam, além dos níveis de hormônios adrenalina e noradrenalina" (CASANOVA "et al" 2009, p. 9). Com isso, é compreendido que os efeitos gerados por essa emoção expressam-se para além do nível psicológico, estabelecendo relação direta com o corpo físico e com a saúde do indivíduo.

De acordo com Navas e Bozal (2012), esta emoção geralmente está associada a situações em que a pessoa valoriza um dano ou ofensa dirigido a si, provocando um sentimento de raiva e indignação. Pode-se dizer que os estímulos mais frequentes que despertam a emoção da raiva estão relacionados às situações que nos fazem entender ou acreditar que fomos traídos, desprezados ou enganados. Em suma, esta emoção possui funções essenciais para a vida, estando relacionada à autoproteção, à regulação interna e à comunicação social (BISQUERRA, 2014).

Por estar presente em todos os seres humanos e culturas, a raiva deve ser compreendida como uma emoção natural e aceitável. No que se refere às pessoas com deficiência, a vivência desta emoção pode ser experimentada de maneira confusa e inconsciente devido às experiências de preconceito e de exclusão social (CROCHIK, 2011). Barcelos (2015) reconhece que a dimensão afetiva e as emoções têm ficado nas penumbras das discussões da sala de aula, na medida em que repercutem as situações de intolerância vivenciadas pelos grupos sociais vulneráveis, suscitando como respostas defensivas a raiva, ira e agressão. Dentro deste grupo, as pessoas com deficiência intelectual tornam-se ainda mais vulnerabilizadas ao serem submetidas a mecanismos de coação e de segregação diariamente na escola e outros espaços sociais. Essa realidade traz consequências na formação de sua identidade, no processo de socialização e nas relações de afetividade com o meio (GLAT, 2004). 
http://dx.doi.org/10.5902/1984686X44426

As pessoas com e sem deficiência devem aprender a identificar, expressar, avaliar e gerir de uma maneira socialmente inteligente as diversas situações sociais que vivenciam. Historicamente os espaços educacionais têm negado a existência das emoções como algo que faz parte da identidade humana e têm se voltado para uma educação estanque, compartimentada, baseada em um currículo unidireccional (ARÁNDIGA, 2007).

A educação emocional surge exatamente como um campo cujas atividades colaboram para a quebra da rigidez e para a falta de afetividade presentes nos espaços sociais (GONSALVES e SOUZA, 2015). Todas as emoções passam a ser vistas como fundamentais para o ser humano, inclusive a emoção da raiva. Ao preparar os/as indivíduos na perspectiva da educação emocional para, primeiramente, saber identificar as emoções em si mesmos e, posteriormente, os auxiliarem no processo de aprender a conviver com elas, o campo da educação emocional estará contribuindo diretamente para o bem-estar e a qualidade de vida, principalmente daqueles que são alvos constantes de conflitos, como é o caso das pessoas com deficiência (DANTAS, 2018).

Nesse sentido, mediante processos de aquisição de habilidades para responder positivamente aos estímulos da raiva, ou seja, por meio da regulação das emoções (CASASSUS, 2009) proporcionada pela Educação Emocional, a pessoa com deficiência intelectual pode encontrar em si um caminho para transpor as situações de vulnerabilidade em que se encontra, tomando consciência de seus direitos enquanto cidadã e pessoa autônoma, tornando-se, assim, protagonista de sua própria história.

\section{Percurso Metodológico}

No que diz respeito aos procedimentos metodológicos, destaca-se que as raízes dessa pesquisa estão no Núcleo de Educação Emocional de uma Universidade Federal, concebida através de um projeto de pesquisa e extensão realizado nos anos de 2016 a 2019, no qual foram trabalhadas as emoções primárias de estudantes com e sem deficiência da escola pública. No caso deste artigo específico, foi realizado um recorte temático e utilizados exclusivamente os dados sobre a emoção da raiva. Este estudo constitui uma parte da pesquisa sobre as emoções realizada somente com estudantes com deficiência intelectual, nos meses de março a julho de 2019.

O campo de pesquisa deste estudo foi uma Escola pertencente à uma Fundação Paraibana especializada no acompanhamento e na assistência voltadas às crianças, jovens e adultos com deficiência. Os participantes da pesquisa foram 27 estudantes com 
deficiência intelectual, matriculados em três turmas, pertencentes à modalidade de Educação de Jovens e Adultos (EJA), oferecida no turno vespertino da Escola. Com relação às questões de gênero, dentre os 27 sujeitos da pesquisa, 19 pertencem ao gênero feminino e 8 pertencem ao gênero masculino, com faixa etária que varia dos 16 aos 35 anos de idade. O critério de escolha desses participantes foi estar matriculado na turma de EJA e possuir acima de 15 anos, pois presumiu-se que esses estudantes teriam uma melhor percepção de si e uma expressão mais clara de seus sentimentos.

No tocante aos instrumentos de pesquisa, foram utilizados dois instrumentos. $O$ primeiro foi a observação direta realizada pelo pesquisador no momento da coleta de dados e registrado logo ao término do dia no diário de bordo, no qual foram anotadas as percepções, falas e sentimentos vivenciados. O segundo foi um roteiro de entrevista semiestruturado, denominado Diário das Emoções. Tal roteiro de entrevista foi aberto, com perguntas sobre quais as situações que faziam com que o respondente sentisse uma determinada emoção (medo, raiva, alegria, dentre outras), solicitando uma descrição do evento. Cada página do Diário correspondeu a uma emoção.

O roteiro de entrevista foi construído e aplicado pela equipe do projeto de pesquisa, constituída por pesquisadores em educação e também validado por pares. A aplicação da entrevista foi realizada presencialmente nos meses de março a julho de 2019. Todos os/as alunos/as presentes nos dias da aplicação da entrevista aceitaram colaborar com a investigação, mostrando-se interessados em participar, não tendo sido registrado nenhum caso de rejeição. Foram cumpridas todas as exigências científicas e éticas, incluindo a confidencialidade, o consentimento da escola e das famílias e a aprovação da pesquisa no Comitê de Ética.

Considerando a necessidade de tornar o instrumento de coleta de dados acessível, devido às peculiaridades de cada aluno/a com deficiência intelectual, adaptamos o Diário das Emoções de forma que os estudantes pudessem responder oralmente às indagações contidas no roteiro e as respostas foram registradas por meio de um gravador de voz. Como método para uma maior sensibilização e compreensão dos jovens sobre a emoção a ser trabalhada, também contamos com o auxílio de materiais lúdicos, como livros ilustrados, jogos didáticos, pintura, filmes, música, etc.

No momento anterior a aplicação do roteiro de entrevista, também foram realizadas vivências em Educação Emocional, com o intuito de trazer uma maior clareza e 
conscientização sobre as emoções para os sujeitos da pesquisa. No caso da vivência sobre a raiva, esta foi dividida em cinco momentos:

1. Contato inicial com a turma e apresentação da emoção "raiva" com a utilização de recursos, imagens de expressões faciais e música.

2. Apresentação de um livro com imagens fotográficas de situações que remetessem à emoção.

3. Técnica de relaxamento com o auxílio de música, após um diálogo com a turma e pergunta oral sobre a emoção contida no Diário.

4. Após a coleta foi proposta uma atividade educativa.

5. Finalização da intervenção, com recolhimento de pinturas, além de agradecimentos a alunos/as e professora.

Após a coleta das informações por meio das vivências e da aplicação do roteiro de entrevista, passou-se, então, para a fase de transcrição dos áudios e caracterização das respostas, através do desenvolvimento de categorias de informação. Cada página do Diário das Emoções, correspondente a uma emoção, foi identificada pelo número do participante: por exemplo, P.16 (Participante número 16); P.02 (Participante número 02). Tal procedimento permitiu selecionar categorias principais, considerando a recorrência do fenômeno. Ao longo do texto, as falas dos jovens estão identificadas pelo número que Ihes foi correspondente e pela letra em itálico.

A última fase da investigação, dedicada à codificação e análise, permitiu, conforme recomenda Creswell (2014), examinar a base de dados coletados considerando o fenômeno estudado, estabelecendo relações e explicações com a literatura estudada, verificando a existência ou não de elementos inovadores.

A seguir, apresenta-se a análise dos dados relativos a vivência da emoção da raiva pelos jovens com deficiência intelectual.

\section{Os estímulos geradores da raiva em jovens com deficiência intelectual}

A partir dos dados coletados nesta pesquisa, foram percebidos alguns estímulos emocionais capazes de levar à vivência da emoção da raiva pelos jovens e adultos com deficiência intelectual. Possebon (2017) orienta que não é qualquer situação que tem o poder de desencadear uma emoção, pois, para que a situação emocione, ela precisa ser um Estímulo Emocional Competente - EEC, termo criado por António Damásio (2013) 
http://dx.doi.org/10.5902/1984686X44426

para designar que toda emoção emerge da avaliação que a pessoa faz da realidade e de seu olhar perante a situação.

Considerando os achados, um dos principais Estímulos Emocionais Competentes capaz de gerar a emoção da raiva entre os jovens com deficiência intelectual está relacionado a situações que evocam a frustração. Um dos sujeitos participantes reflete essa realidade ao mencionar que: "Quando meu tio promete que vai me levar para passear, aí tem dias que ele não pode e eu fico muito brava, porque ele promete e não cumpre" (P.01).

Situações vinculadas ao universo do trabalho, escola, família e amigos, geralmente, são surpreendidas por esse sentimento, denunciado a partir do momento em que se gera uma expectativa diante do outro ou de algo e essa expectativa não é cumprida. O sentimento de frustração ocorrido por meio da existência de um obstáculo que impede a consecução de um objetivo está diretamente relacionado a situações em que as pessoas sentem-se traídas, depreciadas ou enganadas (NAVAS; BOZAL, 2012) e este é um sentimento comum em pessoas com ou sem deficiência.

A pesquisa desenvolvida por Possebon (2019) aponta que adolescentes sem deficiência também sentem raiva quando passam por momentos de frustração, quando, por exemplo, não conseguem aprender, quando tiram notas baixas mesmo tendo estudado, quando pessoas prometem algo para eles/as e não cumprem.

A frustração é vista como fonte de negatividade e problemas para o indivíduo, e espera-se, da mesma forma, que esta seja a razão para que sejam desenvolvidos mecanismos de defesa ou de superação da própria frustração (DE MOURA e PASQUALI, 2006). Nesse sentido, através do desenvolvimento da consciência emocional oportunizado pelos princípios da Educação Emocional, é esperado que a superação de situações que geram o sentimento de frustração aconteça, possibilitando que o sujeito reflita sobre a emoção ocorrida.

Outro Estímulo Emocional Competente capaz de despertar a emoção da raiva nos jovens com deficiência intelectual refere-se ao bullying, o qual compreende atitudes agressivas, intencionais e repetidas, que ocorrem sem motivação evidente, adotadas por um ou mais estudante (s) contra outro (s), causando dor e angústia (LOPES NETO, 2005). A presença do bullying é recorrente no cotidiano das escolas e acomete jovens com ou sem deficiência. Em um estudo desenvolvido na Holanda (MOOIJ T, 2011), 80.770 estudantes relataram como principais motivos para o bullying: aparência física, 
http://dx.doi.org/10.5902/1984686X44426

comportamentos individuais, nível de desempenho escolar, deficiência física ou intelectual, aspectos religiosos, questões de gênero e orientação sexual.

Possebon (2019) revela que é comum adolescentes (sem deficiência) sentirem raiva, porque ficam "zoando" com ele/a ou fazendo brincadeiras de mau gosto. Eles/as relatam que sentem raiva diante da ironia, das "tiradas de brincadeira", quando diminuem o seu valor na frente de outras pessoas ou quando percebem que passam por uma humilhação. No mesmo sentido, os jovens com deficiência desta pesquisa revelam ter 0 mesmo sentimento ao passarem por situações semelhantes: "O que me deixa com raiva é quando a pessoa "manga" de mim só porque tenho deficiência, quando ri de mim eu não gosto, fico com raiva" (P. 10); "Eu fico muito furioso quando mexem comigo na escola porque eles me acham burro" (P. 08).

No caso dos jovens com deficiência, o bullying também se fundamenta em estigmas socialmente atribuídos, como apontado nos depoimentos acima, e é concebido como uma atitude hostil ou negativa para com determinados grupos sociais (ARONSON, 1999). Sobre este aspecto, Silva (2007, p. 57-58) contribui afirmando que,

Esta generalização (ou representação mental) é chamada estereótipo e significa atribuir características pessoais ou motivos idênticos a qualquer pessoa de um grupo, independentemente da variação individual existente entre os membros deste.

A presença do bullying como fator desencadeante da emoção da raiva em jovens com deficiência leva à identificação das inúmeras barreiras sociais e de convívio que os estudantes sofrem enquanto jovens e adultos com deficiência pelo fato de possuírem uma condição diferenciada. No caso dos jovens com deficiência intelectual, esta realidade do bullying é ainda mais agravada, pois há o olhar de "estranhamento" devido às especificidades de compreensão e expressão (DANTAS, 2018). Destaca-se que o bullying pode afetar o campo emocional destes jovens, interferindo, consequentemente, na vida cotidiana dos mesmos. Como seres humanos e sujeitos sociais de direitos e deveres, 0 grupo constituído pelas pessoas com deficiência intelectual é igual a qualquer outro grupo social, independentemente de suas subjetividades físicas ou mentais.

Outro fator preponderante capaz de estimular a emoção da raiva, observado nesta pesquisa, está relacionado a ser impedido de algo. Esse mesmo estímulo também foi observado no estudo realizado por Possebon (2019) com adolescentes sem deficiência, quando se verificou que os conflitos familiares que fazem suscitar a emoção da raiva são muitos e dizem respeito a atos cotidianos quando, por exemplo, a mãe não os deixam 
sair, quando os pais não dão o dinheiro que desejam, ou quando os pais reclamam do filho/a, o que evidencia uma série de impasses e dificuldades cotidianas.

No caso dos jovens com deficiência intelectual, percebeu-se, nessa pesquisa, a relação de tais situações em que são impedidos de fazer algo como fator de obstáculo para o alcance de sua autonomia, podendo ser observado através dos seguintes depoimentos:

"Quando minha tia fica me tirando do sério porque eu gosto de vir para cá. Ela fica se metendo, falando para minha mãe não querendo que eu venha, aí eu fico com raiva. Eu não gosto não, fico chorando e com muita raiva" ( $P$. 01.

"Quando meu pai não deixa eu fazer nada com ele pra ajudar, eu fico com raiva" (P. 02).

Em geral, as pessoas com deficiência e, mais precisamente, as que possuem deficiência intelectual, são cercadas por uma rede de proteção que muitas vezes é inconsciente e involuntária, criada por parte dos seus familiares, professores/as e/ou demais pessoas que estão ao seu redor. Neves (2005) argumenta que o solo no qual é gerado a maior superproteção para as pessoas com deficiência intelectual é no âmbito da família e este constitui um dos principais entraves para uma vida independente.

Com isso, é possível constatar que a autonomia das pessoas com deficiência intelectual passa a ser relativa, ou mesmo desconsiderada, no momento em que são impedidas de realizar algo porque são desacreditadas que são capazes. Por esse ângulo, visto que é natural que as pessoas tomem as suas próprias decisões e façam as suas próprias escolhas, os jovens com deficiência intelectual também devem estar inseridos em sua realidade como autores de suas próprias vidas, adquirindo autonomia e participação em ambientes que antes lhes eram negados. Vale salientar que a ausência da autonomia pode afetar o protagonismo destas pessoas, assim como o bullying e o preconceito podem afetar a autoestima.

As agressões físicas e a violência também surgem como Estímulos Emocionais Competentes da raiva entre os jovens com deficiência intelectual. O estudo realizado por Cavalcante e Minayo (2009) estima que a violência contra crianças e adolescentes com deficiência ocorra numa taxa anual 1,7 vezes maior do que crianças e adolescentes em geral. A pesquisa de Possebon (2019) comprovou essa realidade ao mostrar que a violência física foi identificada como causadora da raiva em pouquíssimos casos nos adolescentes sem deficiência. Em relação aos estudantes com deficiência, as autoras (CAVALCANTE e MINAYO, 2009) discutem que esse risco aumentado está associado 
http://dx.doi.org/10.5902/1984686X44426

aos fatores sociais, culturais e econômicos que criam um imaginário social negativo sobre a deficiência.

Nesta pesquisa, as falas dos estudantes evidenciam que a violência pode ocorrer dentro da própria família:

"O meu tio. Ele me belisca e me bate, diz coisa comigo e eu choro. Ele belisca aqui, belisca aqui e belisca aqui. Eu falei isso e minha mãe disse que ia denunciar ele. Vou falar baixinho" (P. 05).

"O que me deixa com raiva... Quando não deixam eu dormir. Eu não posso dormir na minha cama porque meu pai fica me acordando" (P. 10).

A violência, geralmente, dá-se com maior intensidade no momento em que existem condições desiguais entre a vítima e o agressor, em que muitas vezes este último pode estar no seio familiar ou fazer parte do ciclo de amizades da pessoa violentada. No caso das pessoas com deficiência intelectual, Ferreira (2008) argumenta que a invisibilidade deste grupo social está na raiz de sua vulnerabilidade à violências, seja física, psicológica ou sexual, argumento ratificado pelo Relatório da Assembleia Geral das Nações Unidas It is our world too! (ONU, 2001), o qual denuncia que mundialmente milhões de crianças e adolescentes são submetidos a diferentes formas de violência, punição e abuso. $O$ relatório afirma que: "os maus tratos dentro e fora da família constituem uma causa extremamente séria da deficiência e podem causar desajustes sociais e dificuldades na escola, comprometimentos sexuais, etc" (p.40).

A violência contra este grupo minoritário imprime uma condição de fragilidade à pessoa com deficiência, seja ela de qualquer modalidade, pois esta encontra-se em uma posição vulnerável com relação ao indivíduo sem deficiência. Por este ângulo, a assimetria das relações de poder é marcante entre ambos. Além disso, a relação hierárquica provocada por tal assimetria pode ser multiplicada conforme a severidade do caso, ampliando-se caso a pessoa com deficiência pertença a um grupo de risco, como, por exemplo, o de mulheres ou crianças (WILLIAMS, 2003).

Outro Estímulo Emocional Competente capaz de desencadear a emoção da raiva nos jovens com deficiência intelectual desta pesquisa foi a rejeição/preconceito, o que pode ser percebido na fala a seguir: "Tem uma mãe de uma colega que ela não deixa ela nem conversar comigo... Sinto muita raiva, muito chateada, muito ódio no coração... Sinto tudo isso. A mãe dela chama ela para não falar comigo. Sinto raiva disso..." (P.07).

Os objetos da rejeição/preconceito historicamente estão relacionados, invariavelmente, com os mesmos pontos: crença religiosa, sexualidade, deficiência, 
http://dx.doi.org/10.5902/1984686X44426

gênero, raça/etnia, aparência física. Esses elementos, sob a ótica de uma moral conservadora, podem provocar um conjunto de práticas discriminatórias, agressivas e ser um estímulo para a emoção da raiva (ZAVADIVKER, 2014). Devido à condição e aos estigmas socialmente impostos à pessoa com deficiência, a rejeição acaba por tornar-se uma forma silenciosa e legitimada do preconceito, ocasionando sentimentos de inferioridade para este grupo social.

A fala da estudante acima evidencia que o indivíduo que tem preconceitos fecha-se dogmaticamente em determinadas opiniões, sendo incapaz de buscar conhecimentos sobre o objeto que o faria rever suas posições e, assim, ultrapassar o juízo provisório (SILVA, 2006). Crochík (2011) enriquece o entendimento ao afirmar que o preconceito não tem relação direta com a vítima, mas com quem não consegue deter o ódio a si mesmo, dirigindo-o para outros grupos e pessoas. Esse ódio, fruto da raiva doentia e não regulada, é marca do preconceituoso, mesmo que apareça em suas formas aparentemente mais inofensivas como o desprezo e a indiferença.

Ainda nos dias atuais, a segregação sofrida pelas pessoas com deficiência indica que estas continuam a representar uma ameaça à sociedade. Dessa forma, este grupo minoritário é, cotidianamente, privado de seus direitos enquanto cidadãos, a exemplo da exclusão diante do convívio e da interação social. "Percebe-se que novamente a deficiência aparece relacionada à violência, porém neste caso, não como subproduto desta, mas como condição de suscetibilidade para atos de violência" (CRUZ; SILVA; ALVES, 2007, p. 141).

Os Estímulos Emocionais Competentes investigados nesta pesquisa demonstram que o trabalho acerca da emoção da raiva com jovens e adultos com deficiência intelectual precisa ser melhor projetado e desenvolvido em todos os espaços, principalmente na família e na escola. A raiva é uma emoção primária e universal protetora que, pela ausência de regulação emocional nas pessoas, pode ser manifestada em comportamentos agressivos (POSSEBON, 2019). Assim, há que se verificar as possibilidades de mudança na vivência desta emoção através da implantação de propostas na área da Educação Emocional, a fim de desenvolver a regulação emocional dos jovens com e sem deficiência. Isto porque a Educação Emocional oportuniza ao sujeito um processo de autoconhecimento e possibilita a consciência das suas emoções, podendo reconfigurar o conjunto de respostas agressivas e oferecer as melhores tomadas de decisões perante situações que desencadeiam as emoções. 
O trabalho de Educação Emocional na escola emerge como uma importante ferramenta pedagógica a ser considerada, por contribuir com o desenvolvimento integral do ser humano, principalmente daqueles que vivem em situação de vulnerabilidade, como é o caso das pessoas com deficiência intelectual. Nesses termos, têm-se observado em escala mundial os benefícios dos programas de educação emocional, especialmente no que se refere à eficácia na prevenção de conflitos nas escolas e, consequentemente, na adoção de condutas pró-sociais que envolvem atitudes solidárias e cooperativas (POSSEBON e POSSEBON, 2020), diminuindo processos agressivos e discriminatórios.

\section{Considerações finais}

Nesta pesquisa, foi oferecida a possibilidade de identificar os principais Estímulos Emocionais Competentes que levam a vivência da raiva em estudantes com deficiência intelectual da modalidade de Educação de Jovens e Adultos de uma Escola Estadual do município, de João Pessoa-Paraíba. As situações que mais destacaram-se foram aquelas relacionadas a frustração, a violência e agressões físicas, a falta de autonomia, ao bullying, a rejeição e o preconceito, permitindo que fossem propostas análises críticas sobre estas situações relatadas pelos jovens, as quais trazem a marca da diferença ainda presente na sociedade brasileira.

$\mathrm{Na}$ vivência da frustração, o indivíduo depara-se com o insucesso de uma expectativa, podendo ser um estímulo capaz de disparar a emoção da raiva. Casos de frustração podem ser presenciados nos jovens com deficiência intelectual quando, por exemplo, uma promessa não é cumprida. Com relação à falta de autonomia, a percepção em torno dessa sensação dá-se no momento em que é negada a participação e o protagonismo dos jovens com deficiência em suas próprias vidas, quando estes são impedidos de constituírem as suas histórias. O bullying pode influenciar negativamente na vivência desta emoção devido ao fato de estar associado ao preconceito, no qual, neste caso, está intrínseco ao desrespeito para com as pessoas com deficiência. A violência, geralmente, dá-se com maior intensidade no momento em que existem condições desiguais entre a vítima e o agressor e no caso das pessoas com deficiência intelectual, a vulnerabilidade aumenta ainda mais a probabilidade desse estímulo emocional competente. Por fim, a rejeição e o preconceito também estão muito presentes na vida desse grupo social. Devido à condição e aos estigmas socialmente impostos à pessoa 
com deficiência, a rejeição acaba por tornar-se uma forma silenciosa e legitimada do preconceito, ocasionando sentimentos de raiva e inferioridade para a vítima.

Nesse sentido, através das intervenções firmadas nos Fundamentos da Educação Emocional foi possível compreender algumas experiências emocionais que os estudantes participantes vivenciaram, possibilitando evidenciar a maneira que as questões relacionadas à deficiência continuam a interferir fortemente nas emoções das pessoas que compõem esse grupo social.

Além disso, foi compreendido que a emoção da raiva pode constituir-se quando vivenciada de maneira saudável como uma emoção que tem uma função fundamental na quebra de paradigmas, viabilizando o enfrentamento de situações de fragilidade que as pessoas com deficiência intelectual estão sujeitas. Isso, claro, a partir do momento em que os indivíduos percebem-se conscientes emocionalmente, para que assim, sejam capazes de compreender, no outro, tais acontecimentos.

Conclui-se que a Educação Emocional é direcionada ao contexto escolar como base fundamental da tomada de consciência de si e, por consecutivo, na compreensão em torno do outro, culminando na vivência saudável e harmoniosa das emoções. A Educação Emocional constitui-se como uma ponte para ultrapassar situações que tornam as pessoas com deficiência intelectual vulneráveis e invisíveis.

Assim, a Educação Emocional caracteriza-se como um paradigma educacional emergente, o qual propõe uma prática pedagógica mais sensível ao ser humano, tendo como base o reconhecimento das emoções como aspectos centrais da vida e também fundamentais na aquisição de competências e conhecimentos necessários para o estabelecimento de uma vivência saudável e harmoniosa a nível coletivo, pessoal e ambiental.

Esta pesquisa limitou-se ao estudo da emoção da raiva entre os jovens com deficiência intelectual principalmente na identificação dos estímulos que levam esses jovens a vivenciar esta emoção. Aqui, reconhece-se a complexidade deste tema e a infinidade de possibilidades para investigações futuras, tendo a educação emocional como possibilidade metodológica de pesquisa, no sentido de investigar de forma mais profunda como práticas de educação emocional podem proporcionar às pessoas com deficiência um olhar mais humano e afetivo, podendo assim contribuir para uma inclusão efetiva, dentro ou fora da escola. 
http://dx.doi.org/10.5902/1984686X44426

\section{Referências}

ARÁNDIGA, António Válles. Programa PIECE: Programa de Inteligencia Emocional para la convivência escolar. Madrid: EOS, 2007.

ARÁNDIGA, António Válles e TORTOSA, Consol Válles. Inteligencia Emocional: Aplicaciones Educativas. Valencia: Editorial Promolibro, 2013.

ARONSON, Ellen. Prejudice. In: The Social Animal. New York: Worth Publishers/W.H. Freeman and Company, 1999. p. 304-363.

BARCELOS, Ana Maria Ferreira. Letramento emocional no ensino de línguas. In: TOLDO, Claudia; STURM, Luciane (Orgs.). Letramento: práticas de leitura e escrita. Campinas, SP: Pontes Editores, 2015. p. 65-78.

BISQUERRA, Rafael Alzina. Psicopegagogía de las emociones. Madrid: Sínteses, 2009.

BISQUERRA, Rafael Alzina. Prevención del acoso escolar con Educación Emocional. Bilbao: Editorial Desclée de Brouwer, 2014.

BISQUERRA, Rafael Alzina; GONZÁLEZ, Juan Carlos Pérez; NAVARRO, Esther García. Inteligencia Emocional en Educación. Madrid: Sintesis, 2015.

CASANOVA, Nuno; SIQUEIRA, Sara; MATOS e SILVA, Vitor. Emoções. 2009.

Disponível em: https://goo.gl/2vTKmq. Acesso em: ago. 2019.

CASASSUS, Juan. Fundamentos da Educação Emocional. Brasília: UNESCO, Liber Livros Editora, 2009.

CAVALCANTE, Fátima Gonçalves; MINAYO, Maria Cecília de Souza. Representações sociais sobre direitos e violência na área da deficiência. Ciência e Saúde Coletiva. n.14. v.1. p.57-66, 2009. Disponível em: https://www.scielo.br/scielo.php?pid=S1413$81232009000100011 \&$ script=sci_abstract\&tIng=pt. Acesso em: jan. 2020.

CROCHÍK, José Leon. Preconceito e Inclusão. Webmosaica. V.3. N.1. p. 32-42 (jan-jun), 2011. Disponível em https://seer.ufrgs.br/webmosaica/article/view/22359. Acesso em: fev. 2020.

CRESWELL, John. Investigação Qualitativa e Projeto de Pesquisa. Porto Alegre: Penso, 2014.

CRUZ, Daniel Marinho Cesar da; SILVA, Juliana Testa; ALVES, Heliana Castro. Evidências sobre violência e deficiência: implicações para futuras pesquisas. Revista Brasileira de Educação Especial. Marília, v. 13, n. 1, p. 131-146, 2007. Disponível em: https://www.scielo.br/scielo.php?pid=S141365382007000100009\&script=sci_abstract\&tIng=pt. Acesso em: jul. 2019 
http://dx.doi.org/10.5902/1984686X44426

DAMÁSIO, Antônio. Em busca de Espinosa: prazer e dor na ciência dos sentimentos. São Paulo: Companhia das Letras, 2013.

DAMÁSIO, Antônio. A estranha ordem das coisas: a vida, os sentimentos e as culturas humanas. Lisboa: Círculo de Leitores, 2017.

DANTAS, Taísa Caldas. Experiência de pessoas com deficiência no ensino superior: um olhar sobre a vivência do empoderamento e da autoadvocacia. Revista Educação Especial, v.31, n.62, jul./set. 2018. Disponível em: https://periodicos.ufsm.br/educacaoespecial/article/view/26760. Acesso em: set. 2019.

DE MOURA, Cristiane Faiad; PASQUALI, Luiz. Construção de um teste objetivo de resistência à frustração. Psico USF, Itatiba, v. 11, n. 2, p. 137-146, dez. 2006. Disponível em https://goo.gl/NqByuj. Acesso em:ago. 2018.

FERREIRA, Windyz Brazão. Vulnerabilidade à violência sexual no contexto da escola inclusiva: reflexão sobre a invisibilidade da pessoa como deficiência

REICE. Revista Iberoamericana sobre Calidad, Eficacia y Cambio en Educación, V.6, N. 2, pp. 120-136, 2008.

GAUDENZI, Paula; ORTEGA, Francisco. Problematizando o conceito de deficiência a partir das noções de autonomia e normalidade. Ciência \& Saúde Coletiva, 21(10):30613070, 2016. Disponível em: https://www.scielo.br/scielo.php?pid=S1413-

81232016001003061\&script=sci_abstract\&tIng=pt. Acesso em: set. 2019.

GLAT, Rosana. Auto-defensoria / Auto-gestão: movimento em prol da autonomia de pessoas com deficiência mental - uma proposta político-educacional. Anais do 90 Congresso Estadual das APAEs de Minas Gerais, disponível em CDRom. Belo Horizonte/MG, 2004.

GONSALVES, Elisa Pereira; SOUZA, Andressa Raquel de Oliveira. Educação, vivência emocional e processo libertador. Impulso. Piracicaba • 25(63), 87-100, maio-ago. 2015. Disponível em: https://www.metodista.br/revistas/revistas-

unimep/index.php/impulso/article/view/2102. Acesso em: jul. 2019.

LOPES NETO, Aramis. Bullying: comportamento agressivo entre estudantes. Jornal de Pediatria- Vol. 81, No5(Supl), 2005. Disponível em: https://www.scielo.br/pdf/jped/v81n5s0/v81n5Sa06.pdf. Acesso em: out. 2019.

MARTINS, José Maria. A lógica das emoções na ciência e na vida. Petrópolis: Editora Vozes, 2004.

MARTINS, Lúcia de Araújo Ramos. Fundamentos em educação inclusiva. Natal, RN: Editora da UFRN, 2011.

MAZZOTTA, Marcos José da Silveira. Educação especial no Brasil: história e políticas públicas. 5. ed. São Paulo: Cortez, 2005. 
MELETTI, Silvia Márcia Ferreira; BUENO, Geraldo Silveira. O impacto das políticas públicas de escolarização de alunos com deficiência: uma análise dos indicadores sociais no Brasil. Linhas Críticas, Brasília, DF, v. 17, n.33, p. 367-383, maio/ago. 2011.

Disponível em: http://ppeees.ufms.br/wp-content/uploads/2016/02/meletti-bueno-2011linhas-criticas.pdf. Acesso em: fev. 2020.

MENDES, Eniceia Gonçalves. A radicalização do debate sobre inclusão escolar no Brasil. Revista Brasileira de Educação Especial. V.11. n. 33. Set./dez.2006. Disponível em: https://www.scielo.br/pdf/rbedu/v11n33/a02v1133.pdf. Acesso em: jan. 2020.

MIRA Y LOPEZ, Emilio. Quatro Gigantes da Alma: o medo, a ira, o amor, o dever. Rio de Janeiro: José Olympio, 2012.

MOOIJ, Ton. Differences in pupil characteristics and motives in being a victim, perpetrator and witness of violence in secondary education. Rev Papers Educ. V.26. n.1. p.105-122. 2011. Disponível em: https://www.tandfonline.com/doi/abs/10.1080/02671520903191196. Acesso em: fev. 2020.

NAVAS, José Miguel Mestre. e BOZAL, R. G. La Regulación de las Emociones. Madrid: Ediciones Pirámide, 2012.

NEVES, Tânia Regina Levada. Educar para a cidadania: promovendo a auto-advocacia em grupos de pessoas com deficiência. São Carlos: UFSCAR, 2005. Tese de Doutorado apresentada ao Programa de Pós-Graduação em Educação Especial da Universidade Federal de São Carlos.

ONU. Convenção sobre os Direitos das Pessoas com Deficiência (2006). Disponível em: http://www.assinoinclusao.org.br/downloads/convencao.pdf . Acesso em: dez. 2019.

ONU. It is our world too!. Relatório sobre a vida de crianças com deficiência. Assembléia Geral das Nações Unidas Sessão Especial sobre Crianças, 2001. Disponível em: http://www.assinoinclusao.org.br/downloads/convencao.pdf. Acesso em: jan. 2020.

POSSEBON, Elisa Gonsalves. O universo das emoções: uma introdução. João Pessoa: Libellus, 2017.

POSSEBON, Elisa Pereira Gonsalves. Raiva, agressão e educação: um diálogo necessário. Revista Unisinos. V. 23. N.1. 2019. Disponível em:

http://revistas.unisinos.br/index.php/educacao/article/view/edu.2019.231.10. Acesso em: mar. 2020.

POSSEBON, Elisa Pereira Gonsalves; POSSEBON, Fabrício. Descobrir o afeto: uma proposta de educação emocional na escola. Revista Contexto e Educação. Ano 35. N. 110. Jan/Abr. 2020. Disponível em:

https://www.revistas.unijui.edu.br/index.php/contextoeducacao/article/view/8925. Acesso em: jul. 2020. 
RODRIGUES, Ana Paula Neves; LIMA, Cláudia Araújo de. A história da pessoa com deficiência e da educação especial em tempos de inclusão. Interritórios Revista de Educação. Universidade Federal de Pernambuco. Caruaru, V.3, N.5, 2017. Disponível em: https://periodicos.ufpe.br/revistas/interritorios/article/view/234432. Acesso em: mar. 2020.

SILVA, Adriana Nunan do Nascimento. Homosexualidade e Discriminação: o preconceito sexual internalizado. 2007. Disponível em: https://goo.gl/GXXtQP. Acesso em: ago. 2019.

SILVA, Luciene Maria da. O estranhamento causado pela deficiência: preconceito e experiência. Revista Brasileira de Educação v. 11 n. 33 set./dez. 2006b. Disponível em: http://www.scielo.br/pdf/rbedu/v11n33/a04v1133.pdf. Acesso em: dez. 2019.

WILLIAMS, Lucia Cavalcanti de Albuquerque. Sobre deficiência e violência: reflexões para uma análise de revisão de área. Revista Brasileira de Educação Especial. Marília, Jul.Dez. v.9, n.2, p.141-154, 2003. Disponível em:

http://www.laprev.ufscar.br/documentos/arquivos/artigos/2003-williams.pdf. Acesso em: dez. 2019.

ZAVADIVKER, María Natalia. Acerca del valor adaptativo del asco moralizado desde una perspectiva evolucionista. Ideas y Valores, vol. LXIII, n.154, p. 243-269, abr. 2014. Disponível em: http://www.scielo.org.co/pdf/idval/v63n154/v63n154a10.pdf. Acesso em: jul. 2019.

\section{Correspondência}

Taísa Caldas Dantas - Universidade Federal da Paraíba, Centro de Educação, Via Expressa Padre Zé, Conj. Pres. Castelo Branco III, João Pessoa, Paraíba - Brasil.

CEP: $58033-455$

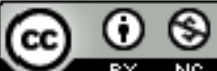

4.0 International (CC BY-NC 4.0) 